\title{
Magnetic resonance coupling for 5G WPT applications
}

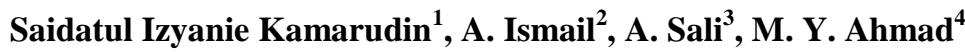 \\ ${ }^{1,2,3}$ Wireless and Photonic Networks Research Centre of Excellence (WiPNet), Department of Computer and \\ Communication System Engineering, Faculty of Engineering, UPM, Serdang, Selangor, Malaysia \\ ${ }^{4}$ Department of Biomedical Engineering, University of Malaya (UM), Kuala Lumpur, Malaysia
}

\begin{tabular}{l} 
Article Info \\
\hline Article history: \\
Received Dec 29, 2018 \\
Revised Mar 2, 2019 \\
Accepted Mar 29, 2019 \\
\hline
\end{tabular}

Keywords:

$5 \mathrm{G}$

Inductive coupling

Magnetic resonance coupling

Wireless power transfer

\begin{abstract}
Inductive Wireless Power Transfer (IWPT) is the most popular and common technology for the resonance coupling power transfer. However, in 2007 it has experimentally demonstrated by a research group from Massachusets Institute of Technology (MIT) that WPT can be improved by using Magnetic Resonance Coupling Wireless Power Transfer (MRC WPT) in terms of the coupling distance and efficiency. Furthermore, by exploiting the unused, high-frequency mm-wave band which are ranging from $3 \sim 300 \mathrm{GHz}$ frequency band, the next $5 \mathrm{G}$ generations of wireless networks will be able to support a higher number of devices with the increasing data rate, higher energy efficiency and also compatible with the previous technology. In this work, a square planar inductor with the dimension of $6.1 \times 6.1 \mathrm{~mm}$ is designed, and the resonators have the same self-resonance frequency at 14 GHz. The coil resonators have been laid on Silicon and Oxide substrate to reduce the loss in the design. From the CST software simulation and the analytical model in MATLAB software, it has been shown that the MRC WPT design has improved the performance of IWPT design by $40 \%$ power transfer efficiency. MRC WPT design also has larger H-Field value which is $705.5 \mathrm{~A} / \mathrm{m}$, as compared to the IWPT design which has only $285.6 \mathrm{~A} / \mathrm{m}$ when both Transmitter(Tx) and $\operatorname{Reciever(RX)}$ is at $0.3 \mathrm{~mm}$ coupling distance.
\end{abstract}

Copyright (c) 2019 Institute of Advanced Engineering and Science. All rights reserved.

\section{Corresponding Author:}

Saidatul Izyanie Kamarudin

Wireless and Photonic Networks Research Centre of Excellence (WiPNet),

Dept. of Computer and Communication Systems Engineering,

Faculty of Engineering, UPM,

43400 Serdang, Selangor C, Malaysia.

Email: yanie_izz@yahoo.com

\section{INTRODUCTION}

The technology of magnetic resonant coupling wireless power transfer (MRC-WPT) takes advantage of two electromagnetic systems with the same resonance coil frequency to transfer energy at a certain distance. In general, when two electromagnetic system is a weak coupling at a certain distance, the system can excite strong magnetic resonance if the natural resonance frequency is the same [1]. Inductive coupling was the most popular and common technology before the resonance coupling evolution. The idea of transmitting power through the air has been found over a century with Nikola Tesla pioneering the experiments and the ideas [2] However, inductive coupling could transmit power only in a short distance as compared to the magnetic resonance coupling as the system efficiency is significantly affected by the coil's axial and angular misalignment[2]. In 2007, a research group from Massachusets Institute of Technology (MIT) has experimentally demonstrated an efficient non-radiative power transfer over distance up to 8 times the radius of the coils using a 4-coils strongly coupled magnetic resonance magnetic system, and transferred 60 Watts of power with over $40 \%$ efficiency up to 2 meters in distance [3,4]. 
Fifth generation (5G) technology is the next step in the evolution of wireless power transfer technology which aims to provide connectivity for any electrical devices, increasing data rate, higher energy efficiency as well as having compatibility with the previous technologies. The ultimate goal of 5G technology is successful in managing future wireless devices requirements. Varieties of $5 \mathrm{G}$ enabling technologies have been developed which includes extending the wireless communication to the higher frequency band, the advances development of multi-band antenna as well as wireless power transfer system [5]. Also, to realise the vision of the Internet of Things/Internet of Everythings(IoT/IoE), the 5G technology is aimed to be able to support the significant number of devices connected with reduced cost per information transfer [6]. According to [7], the mobile traffic is expected to increase by $60 \%$ per year due to the increasing number of electronic devices. Thus, the critical essence of the next $5 \mathrm{G}$ generation wireless networks is to explore and exploit the unused high-frequency mm-wave band which ranging from $3 \sim 300 \mathrm{GHz}$ frequency band [8].

Furthermore, as stated by [9] when the operating frequency of coil approaches the self-resonance frequency of the coil, the parasitic resistance will increase drastically. Furthermore, the coil also behaves as a capacitor for a frequency higher than a the self-resonance frequency. Thus it cannot be used as an inductor. In this system, the coil can be used for the 5G WPT applications which the operating frequency is below than the self-resonance frequency of the coil which is $14 \mathrm{GHz}$ in order to have a maximum power transfer efficiency.

Previous work has been done in wireless power transfer application in RF Identification devices in the $\mathrm{GHz}$ frequency band. However, the size is too small, and most of the works are on the complementarymetal-oxide-semiconductor (CMOS) technology using an on-chip antenna (OCA) [10]. Also, the OCA UHF tags are using inductive coupling as a power transfer method in the CMOS system. For instance, at $4.7 \mathrm{GHz}$ frequency, [11] has reported the OCA design which is fabricated using $65 \mathrm{~nm}$-CMOS technology with the coil area of $0.01 \mathrm{~mm}^{2}$ with the read range at $1.2 \mathrm{~mm}$ distance. At $2 \mathrm{Ghz}$ frequency, [12] has design OCA with the coil antenna area $0.04 \mathrm{~mm}^{\wedge} 2$ with the read distance at $1.1 \mathrm{~mm}$. At $2.45 \mathrm{GHz}$ frequency [13-16] has reported the OCA design using $130 \mathrm{~nm}-\mathrm{CMOS}$ and post-processing with coil antenna area $0.5 \mathrm{~mm}^{\wedge} 2$ and the read range is at $0.5 \mathrm{~mm}$ distance.

In this work, a square planar inductor coil with the size of $6.1 \mathrm{~mm}$ x $6.1 \mathrm{~mm}$ which is laid on Silicon and Oxide is designed for both IP and MRC WPT systems. The size of the resonators is much larger as compared to the resonators that have been reported before, so the applications of the 5G WPT are not only limited into the OCA and CMOS system. Analytic equations are used to explain the design for both IWPT and MRC WPT system. Furthermore, 3-Dimensional (3-D) and B-Field Electromagnetic (EM) simulation in CST software shown that the four-coils WPT system has outperformed the 2-coils WPT by up to $40 \%$ power transfer efficiency at $0.3 \mathrm{~mm}$ distance. Both efficiencies of IWPT and MRC WPT designs in CST are also compared in the theoretical calculation in MATLAB, and the efficiencies versus distance differential errors are not more than $5 \%$

\section{RESEARCH METHOD}

Several closed-form equations have to be considered in designing the PSCs MCR-WPT system. Figure 1 shows the design of schematic square spiral coils in CST software. Figure 2 and Figure 3 shows the equivalent circuit model of the IWPT and MRC-WPT system respectively by taking into account all mutual inductance in the MRC-WPT for 5G applications [17-19]. According to [18, 20, 21] an accurate expression for inductance value $\mathrm{L}$ is:

$$
\mathrm{L}=\frac{\mu_{0} n^{2} D_{a v g} C 1}{2}\left(\ln \left(\frac{C 2}{\rho}\right)+C 3 \rho+C 4 \rho^{2}\right)
$$

Where the magnetic permeability of free space, $\mu_{o}$ can be defined as $4 \pi \times 10^{-7} \mathrm{H} / \mathrm{m}$, and the fill ratio, $\rho$ and can be calculated as below:

$$
\rho=\frac{D_{\text {out }}-D_{\text {in }}}{D_{\text {out }}+D_{\text {in }}}
$$

While the average diameter, $D_{\text {avg }}$ is and can be calculated as:

$$
D_{\text {avg }}=\frac{D_{\text {in }}+D_{\text {out }}}{2}
$$

Besides $C_{1}, C_{2}, C_{3}$, and $C_{4}$, the layout depending factors are being shown in Table 1[22]. 
Table 1. Coefficients factors for square inductor

\begin{tabular}{ccccc}
\hline Layout & $C_{1}$ & $C_{2}$ & $C_{3}$ & $C_{4}$ \\
\hline Square & 1.27 & 2.07 & 0.18 & 0.13 \\
\hline
\end{tabular}

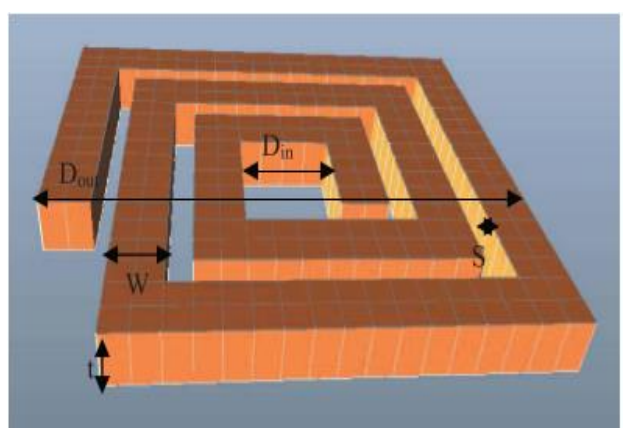

Figure 1. Square spiral coils schematic design

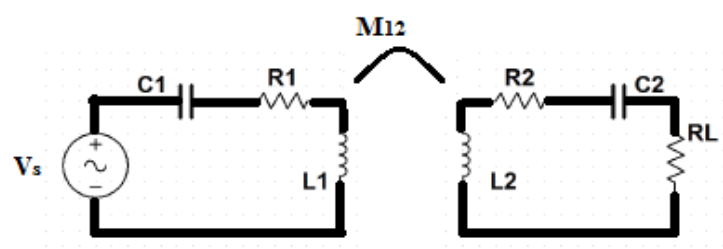

Figure 2. Equivalent Curcuit Model for IWPT

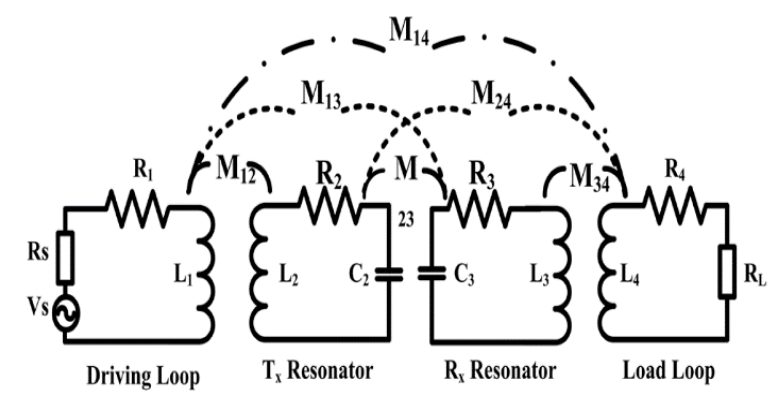

Figure 3. Equivalent circuit model for MRC WPT

According to [23] the self-capacitance in each spiral coils due the distance between the turns in the square spiral coil can be calculated by:

$$
C_{S}=\mathrm{n} W^{2}\left(\frac{\varepsilon_{o x}}{t_{o x, M 1-M 2}}\right)
$$

Where $\mathrm{n}$ is the turn's numbers, $\mathrm{W}$ is the metal width, $t_{o x, M 1-M 2}$ is the distance between the turns and $\varepsilon_{o x}=3.45 \times 10-11 \mathrm{~F} / \mathrm{m}$ is the oxide permittivity. The metal loss mechanism modelled by series resistance in the inductor is:

$$
R_{S}=\frac{\rho l}{W \delta\left[1-e^{\frac{-t}{\delta}}\right]}
$$

Where $l$ the total length of the inductor, the resistivity of the metal is called $\rho$, the metal thickness in micron meter is called $t$, and the the skin effect depth is called $\delta$, which can be calculated as:

$$
\delta=\sqrt{\frac{\rho}{\pi \mu f}}(\mu \mathrm{m})
$$

Where the frequency in $\mathrm{GHz}$ is called $f$ and the magnetic permeability is called $\mu$.

The mutual inductance between the planar inductors can be expressed using the Neumann's equation [24].

$$
\mathrm{M}=\frac{\mu_{0}}{4 \pi} \oint_{c 1} \oint_{c 2} \frac{1}{R} d \overrightarrow{l_{1}} \cdot d \overrightarrow{l_{2}}
$$


Where $\mathrm{R}=\sqrt{a^{2}+b^{2}+z^{2}-2 a b \cos \left(\varphi_{1}-\varphi_{2}\right)}$. Thus, $\mathrm{M}$ can be expressed as:

$$
\mathrm{M}=\frac{\mu_{0} a b}{4 \pi \sqrt{a^{2}+b^{2}+z^{2}}} \int_{\varphi=0}^{\varphi=2 \pi} \frac{\cos \left(\varphi_{1}-\varphi_{2}\right)}{1-\frac{2 a b}{a^{2}+b^{2}+z^{2}}} \cos \left(\varphi_{1}-\varphi_{2}\right)
$$

The mutual inductance can be further simplified into (8) as in wireless applications, the distance in the middle of the coils usually is smaller as compared to the radius coil [7].

$$
\mathrm{M}=\frac{\mu_{o} \pi a^{2} b^{2}}{2\left(a^{2}+b^{2}+z^{2}\right)^{\frac{3}{2}}}\left(1+\frac{15}{32} \gamma^{2}+\frac{315}{1024} \gamma^{4}\right)
$$

If the separation between the coils is huge $\left(\mathrm{z}>>r_{\min }\right.$, where $r_{\min }$ is the minimum radius of the primary coil or secondary coil), the equation can be further reduced again to (9)

$$
\mathrm{M}=\frac{\mu_{o} \pi a^{2} b^{2}}{2\left(a^{2}+b^{2}+z^{2}\right)^{\frac{3}{2}}}
$$

The square inductor $(6.1 \mathrm{~mm} \times 6.1 \mathrm{~mm})$ is designed on the Silicon substrate layer $(7 \mathrm{~mm} \times 7 \mathrm{~mm})$ with a thickness of $0.2 \mathrm{~mm}$, an oxide layer $(7 \mathrm{~mm} \times 7 \mathrm{~mm})$ with the thickness of $0.05 \mathrm{~mm}$. For small coils design, it is essential to choose the substrate and material to obtain low loss design. Besides, due to the gap in between the inductor and the substrate, outflow current to the substrate is zero and eddy current in the in the substrate will be reduced to zero hence the losses are also reduced [25]. The critical parameters in designing the coils are space between the turns (S), width of the coil (W), number of the coils turn $(\mathrm{N})$, metal thickness $(\mathrm{t})$, the inductor shape (in this design it is square), and the total length of the inductor (L) which will determine the inductance value of the coil. Table 2 shows the parameters dimension for each coil in both IWPT and MRC-WPT designs.

Table 2. Parameter summary for 4-coils design

\begin{tabular}{cc}
\hline Coil Parameters & Dimension \\
\hline W, width (mm) & 0.2 \\
S, spacing (mm) & 0.15 \\
N turns & 2.5 \\
t, thickness (mm) & 0.035 \\
Dout, Diameter out (mm) & 6.1 \\
Lengths (mm) & 44.9 \\
L, Inductor (nH) & 72.056 \\
Rs, (parasitic) $\Omega$ & 0.926 \\
Cs, (parasitic) pF & 23 \\
d, distance Rx to Tx (mm) & 0.3 \\
Coupling Coeff. (k) & 0.0869 \\
\hline
\end{tabular}

\subsection{Modelling and analysis of two-coils coupling structure}

The traditional inductive coupling wireless power transfer's principle (IWPT) is based on the two coils position near to each other. As shown in Figure 2, the system consists of transmitting (Tx) resonance coil's curcuit and a receiving $(\mathrm{Rx})$ resonance coil's curcuit. In the Tx and $\mathrm{Rx}$, the resistors, capacitors and inductor are connected in series. L1 and L2 are the self-inductance of the Tx and Rx coil. R1 and R2 are the parasitic resistance of the Tx and Rx coils respectively, and $\mathrm{C} 1$ and $\mathrm{C} 2$ are the parasitic capacitance in the coils of Rx and Tx. Vs is the Sine voltage supply, and RL is the load. M is the mutual inductance between Tx coil and Rx coil [26]. An AC magnetic flux is produced when an AC current is flowing through the Tx coil or primary coil. The Rx coil or secondary coil is then picked up this flux and is converted into an AC voltage across it [27]. Using the circuit theory, the transmission coefficient $\left(S_{21}\right)$ and $\left(Z_{\text {in }}\right)$ can be obtained as equation below [1].

$$
\left[\begin{array}{l}
I_{1} \\
I_{2}
\end{array}\right]=\left[\begin{array}{ll}
Z_{11} & j w M_{12} \\
Z_{22} & j w M_{12}
\end{array}\right]^{-1}=\left[\begin{array}{c}
V_{s} \\
0
\end{array}\right]
$$

We assumed that the impedance of each coil is:

$$
Z_{11}=R_{1}+j w L_{1}+\frac{1}{j w C_{1}}
$$




$$
Z_{22}=R_{2}+j w L_{2}+\frac{1}{j w C_{2}}
$$

The coefficient of mutual inductance in the middle of Tx and Rx coils can be calculated using (13).

$$
M_{12}=K_{12} \sqrt{L_{1} L_{2}}
$$

In conclusion, the system efficiency of the system in this work is defined by the scattering parameters $\left(S_{21}\right)$ of the two-port network which can be calculated as below:

$$
S_{21}=2 \frac{V_{0}}{V_{s}}\left(\frac{R_{1}}{R_{2}}\right)^{\frac{1}{2}}
$$

\subsection{Modelling and analysis of four-coils coupling structure}

The MRC-WPT system as shown in Figure 3 consists of four components which are; a source coil, a transmitting and receiving resonating coils, and a load coil. In this system, the energy is transferred via inductive coupling through the driver loop and the transmitter resonator. Then, the energy is transferred from the Tx resonator coil to the Rx resonator coil via magnetic resonance coupling. Both resonators from the Tx and $\mathrm{Rx}$ are resonated at the same frequency which is in this work the self-resonance frequency is at $14 \mathrm{GHz}$. The MRC-WPT system can transmit the energy in a longer distance as compared to the IWPT system. However, the efficiency of the MRC-WPT system will also decrease rapidly with the factor of optimal distance [28]. From [28,29] the transmmision effeciency coeffienct of four-port network scattering parameters $\left(S_{21}\right)$ and $\left(Z_{i n}\right)$ can be calculated as equations below:

$$
\begin{aligned}
& {\left[\begin{array}{l}
I 1 \\
I 2 \\
I 3 \\
I 4
\end{array}\right]=\left[\begin{array}{cccc}
Z 11 & (j \omega M 12)(j \omega M 13) & (j \omega M 14) \\
(j \omega M 12) & Z 22 & (j \omega M 23) & (j \omega M 24) \\
(j \omega M 13) & (j \omega M 23) & Z 33 & (j \omega M 34) \\
(j \omega M 14) & (j \omega M 24)(j \omega M 34) & Z 44
\end{array}\right]^{-1}\left[\begin{array}{l}
V 1 \\
V 2 \\
V 3 \\
V 4
\end{array}\right]} \\
& \mathrm{Z}_{11}=\left(\mathrm{R}_{\mathrm{s}}+\mathrm{R}_{1}+\mathrm{j} \omega \mathrm{L}_{1}+\frac{1}{j \omega C 1}\right) \\
& \mathrm{Z}_{22}=\left(\mathrm{R}_{2}+\mathrm{j} \omega L 2+\frac{1}{j \omega C 2}\right. \\
& \mathrm{Z}_{33}=\left(\mathrm{R}_{3}+\mathrm{j} \omega L 3+\frac{1}{j \omega C 3}\right) \\
& \mathrm{Z}_{44}=\left(\mathrm{R}_{4}+\mathrm{R}_{\mathrm{L}}+\mathrm{j} \omega L 4+\frac{1}{j \omega C 4}\right)
\end{aligned}
$$

Where C1, C2, C3 and C4 are the parasitic capacitances of each inductor. Both $R_{\text {Source }}$ and $R_{\text {Load }}$ is $50 \Omega$ [29]. Thus, According to $[1,30]$ :

$$
\begin{aligned}
& Z_{\text {in }}=\frac{V_{s}}{I_{1}}-Z_{s} \\
& S_{21}=2 \frac{V_{0}}{V_{s}}\left(\frac{R_{1}}{R_{4}}\right)^{\frac{1}{2}}
\end{aligned}
$$

\section{RESULTS AND ANALYSIS}

For both IWPT and MRC WPT, all the coils have been designed with the same size and structure, without any tuning capacitance is being inserted in the coils. Each of the coils is resonated at $14 \mathrm{GHz}$ selfresonance frequency. Figure 4 shows each of the square spiral resonator designed in CST system and Figure 5 shows the resonance frequency in CST simulation software for each resonator coil. 


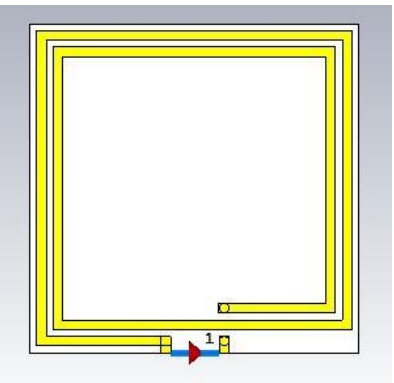

(a)

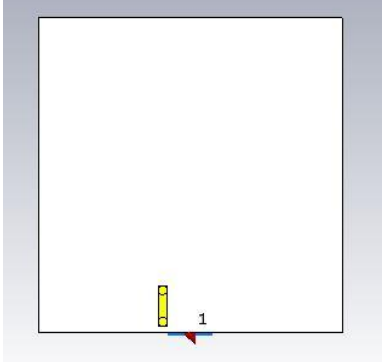

(b)

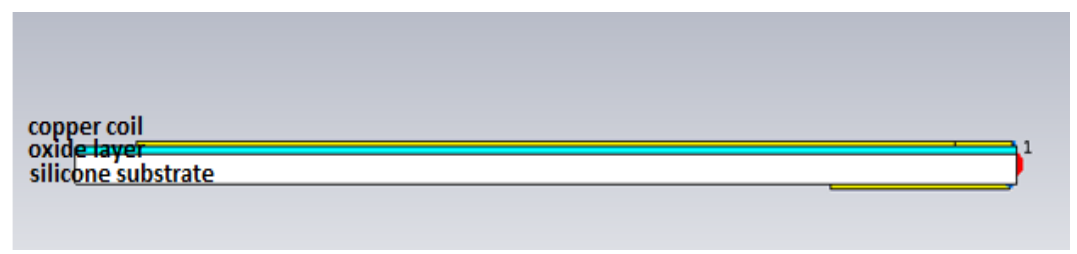

(c)

Figure 4. Square spiral coil in CST, (a) Front-view, (b) Back-view, (c) Side-view

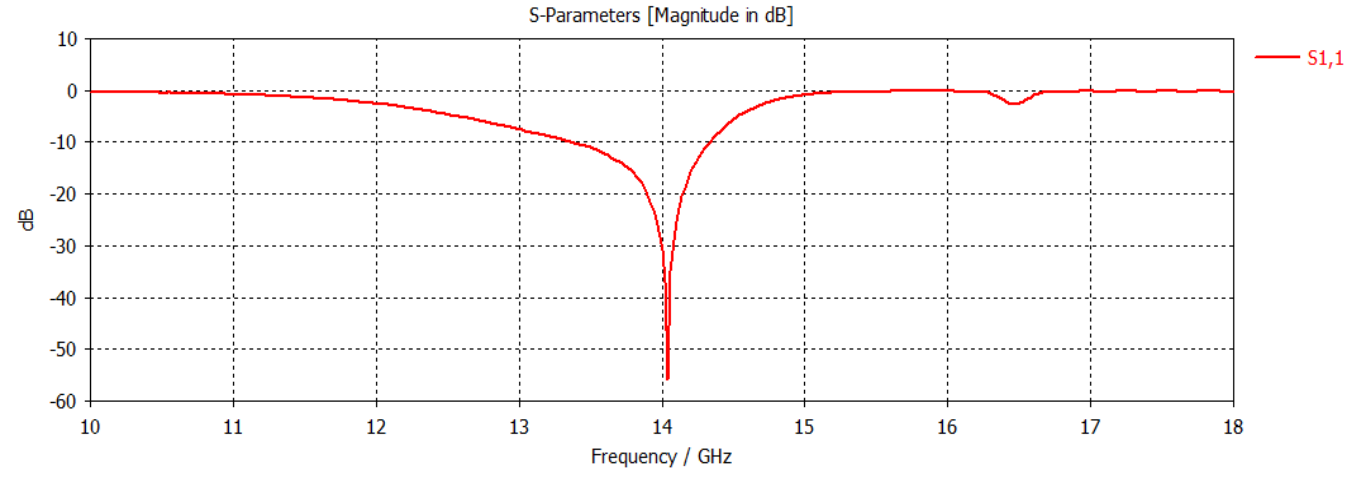

Figure 5. The self-resonance frequency of each coil

\subsection{Two-coils IWPT EM simulations and MATLAB results}

The IWPT design consists of 2-coils which are positioned near to each other. Each of the coils is referred to as a transmitting (Tx) coil and receiving ( $\mathrm{Rx})$ coil (represented as 1 and 2 in the Figure 6(a)). The distance between the Tx coil and the Rx coil is fixed at $0.3 \mathrm{~mm}$, so the performance can be compared with the 4-coils system. Figure 6(b) shows the H-field of IPWPT design in CST software. At lower frequency from the self-resonance which at $5.8 \mathrm{GHz}$ frequency, it can be seen that the maximum $\mathrm{H}$-field of 2-coils IPWT is $285.6 \mathrm{~A} / \mathrm{m}$ when the distance between Tx and Rx is $0.3 \mathrm{~mm}$. It also can be seen from the CST simulation as in Figure 7, the highest efficiency achieved for 2-coils IWPT is $80 \%$ at $0.1 \mathrm{~mm}$ distance. However, the efficiency only works for a short distance, and it is rolled down too quickly below than $20 \%$ when the coupling distance is at $0.3 \mathrm{~mm}$. 


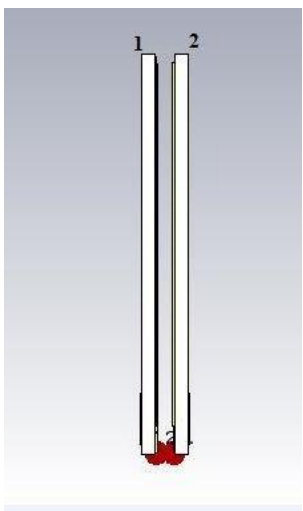

(a)

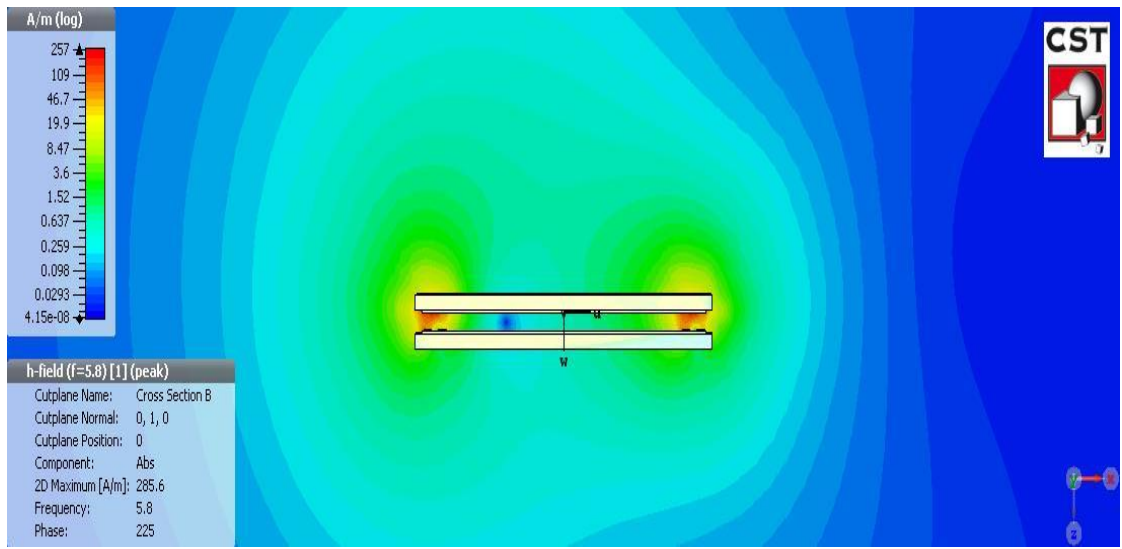

(b)

Figure 6. (a)IWPT coils in CST, (b) H-field of IWPT in CST

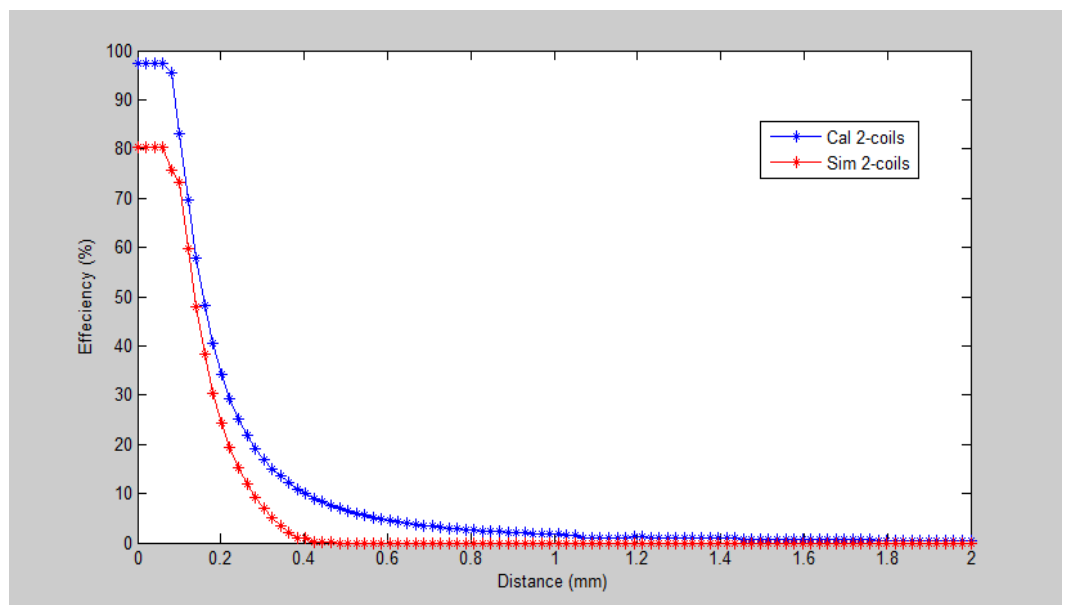

Figure 7. IWPT efficiencies at different distance, calculated versus simulated

\subsection{Four-coils IWPT EM simulations and MATLAB results}

As compared to the IWPT design system, the MRC WPT design system in figure consist of 4-coils, which each of the coils is referred as driver coil, primary coil, a secondary coil, and load coil (represent as 1,2,3,4 in Figure 8(a)). Also, the Figure 8(b) shows the H-field for the 4-coils MRC-WPT design in CST software. The most region around the 4-coils MRC-WPT system is green in colour. The maximum intensity of $\mathrm{H}$-field when the frequency is at $5.8 \mathrm{GHz} \mathrm{GHz}$ is $705.5 \mathrm{~A} / \mathrm{m}$ when the coupling (k) between the Transmitter (Tx) and Receiver (Rx) is at $0.3 \mathrm{~mm}$ in the distance.

Besides, from the observation in CST software, when the distance is varied, there are some variations in resonance frequency. However, maximum efficiency does not change. From Figure 9, it can be seen that the highest efficiency achieved is $61.38 \%$ when $\mathrm{Tx}$ and $\mathrm{Rx}$ are at $0.3 \mathrm{~mm}$ distance. Also, the comparison between mathematical and simulation is made, and the results are significant as they gave a clear expression of the system behaviour in order to prepare for the measurement testing in the real environment. 


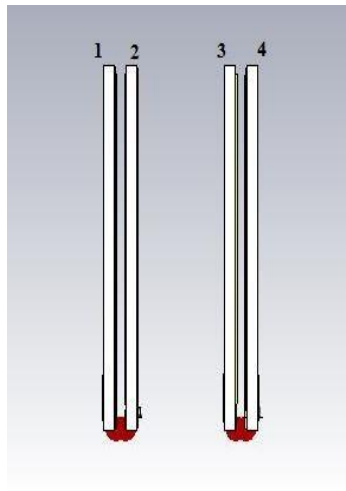

(a)

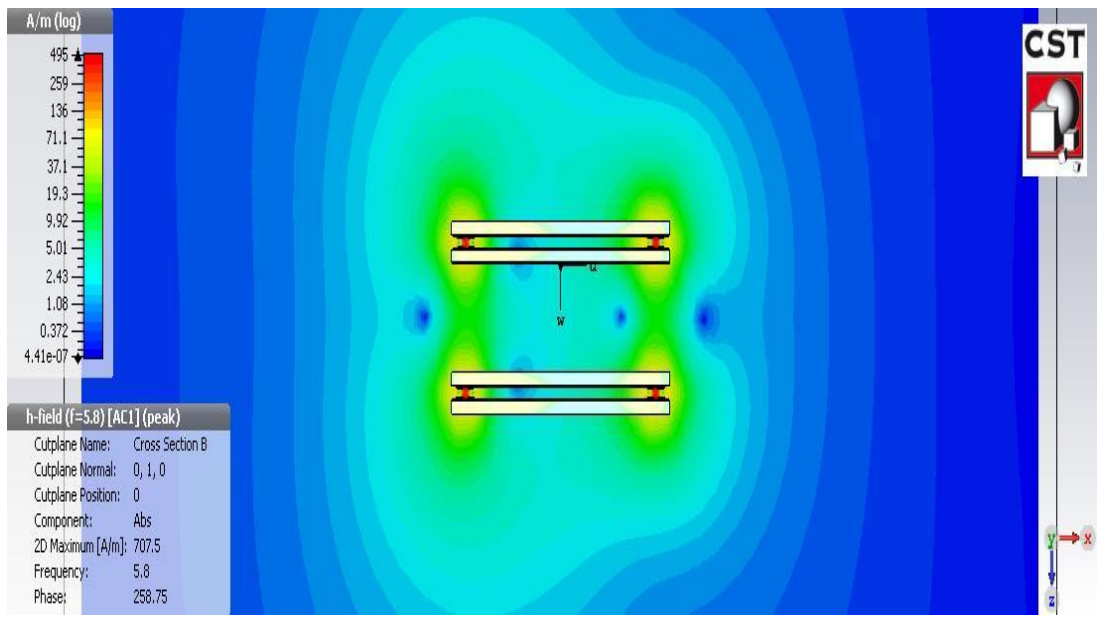

(b)

Figure 8. (a)MRC-WPT coils in CST, (b) H-Field of MRC-WPT in CST

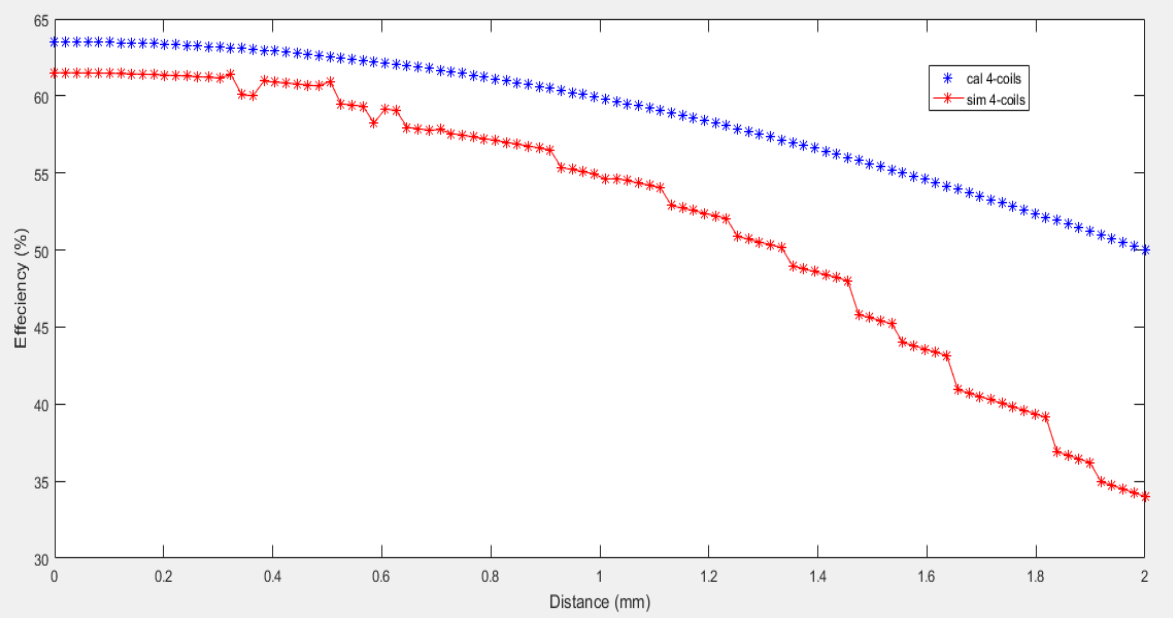

Figure 9. MRC-WPT efficiencies at different distance, calculated versus measured

\section{CONCLUSION}

To summarised, the 2-coils IWPT and 4-coils MRC WPT for 5G wireless power transfer applications have been simulated and analysed in the CST and MATLAB software. From the results, it can be proved that the 4-coils MRC WPT design has outperformed the 2-coils IWPT design by up to $40 \%$ of power transfer efficiency. The 4-coils MRC WPT has $61.38 \%$ power transfer efficiency when the Tx and Rx are at $0.3 \mathrm{~mm}$ distance, while the 2-coils IWPT dropped to below $20 \%$ power transfer efficiency at the same coupling distance of Tx and Rx. It can also be seen that the IWPT efficiency rolled down faster to $0 \%$ efficiency when the coupling distance is at $1 \mathrm{~mm}$ while 4-coils MRC WPT still having more than $40 \%$ power transfer efficiency when the coupling distance is at $1 \mathrm{~mm}$. Furthermore, the square coil resonators dimension are 6.1x6., which they are much larger than the previously reported design so that the applications by using these resonator coils are not only limited into the OCA and CMOS system power transfer.

\section{ACKNOWLEDGEMENTS}

The authors express their thanks and gratitude to the University Putra Malaysia (UPM), Grant Putra 2016(Project No: GP-IPS/2016/9488800), and ATOM- Advancing the State of the Art of MIMO: The Key to Successful Evolution of Wireless Networks (Project No.: 690750-ATOM-H2020-MSCA-RISE-2015, UPM: 6388800-10801) for the technical and the financial support. 


\section{REFERENCES}

[1] L. Gao et al., "Magnetic coupling resonant wireless energy transmission coil quantitative relation modeling and simulation research," 2013 10th IEEE International Conference on Control and Automation (ICCA), Hangzhou, 2013, pp. 202-207.

[2] S. Park, H. Kim, J. Cho, E. Kim and S. Jung, "Wireless power transmission characteristics for implantable devices inside a human body," 2014 International Symposium on Electromagnetic Compatibility, Gothenburg, pp. 1190-1194, 2014.

[3] Nukala, B. T., Tsay, J., Lie, D. Y. C., Lopez, J., \& Nguyen, T. Q. "Efficient near-field inductive wireless power transfer for miniature implanted devices using strongly coupled magnetic resonance at $5.8 \mathrm{GHz}$ ". 2016 Texas Symposium on Wireless and Microwave Circuits and Systems, WMCS 2016, 4-7. 2016.

[4] YC Lie, D. "Wireless Power Transfer (WPT) using Strongly Coupled Magnetic Resonance (SCMR) At 5.8 GHz for Biosensors Applications: A Feasibility Study by Electromagnetic (EM) Simulations”. International Journal of Biosensors \& Bioelectronics, 2(2). 2017.

[5] R. W. Jones and K. Katzis, "5G and wireless body area networks," 2018 IEEE Wireless Communications and Networking Conference Workshops (WCNCW), Barcelona, 2018, pp. 373-378.

[6] Barman, S. Das, Reza, A. W., Kumar, N., Karim, M. E., \& Munir, A. B. "Wireless powering by magnetic resonant coupling: Recent trends in wireless power transfer system and its applications". Renewable and Sustainable Energy Reviews, 51, 1525-1552. July 2015.

[7] A. Costanzo and D. Masotti, "Energizing 5G: Near- and Far-Field Wireless Energy and Data Trantransfer as an Enabling Technology for the 5G IoT," in IEEE Microwave Magazine, vol. 18, no. 3, pp. 125-136, May 2017.

[8] Ghebleh, R., \& Ghaffari, A. "A Comprehensive survey on 5G: The prospect of future communications". Journal of Network and Computer Applications. pp. 1-32, 2017.

[9] A. K. RamRakhyani, S. Mirabbasi and M. Chiao, "Design and Optimization of Resonance-Based Efficient Wireless Power Delivery Systems for Biomedical Implants," in IEEE Transactions on Biomedical Circuits and Systems, vol. 5, no. 1, pp. 48-63, Feb. 2011.

[10] J. Grosinger, W. Pachler and W. Bosch, "Tag Size Matters: Miniaturized RFID Tags to Connect Smart Objects to the Internet," in IEEE Microwave Magazine, vol. 19, no. 6, pp. 101-111, Sept.-Oct. 2018.

[11] N. Kuo, B. Zhao and A. M. Niknejad, "Inductive Wireless Power Transfer and Uplink Design for a CMOS Tag With $0.01 \mathrm{~mm} 2$ Coil Size," in IEEE Microwave and Wireless Components Letters, vol. 26, no. 10, pp. 852-854, Oct. 2016.

[12] Nai-Chung Kuo, Bo Zhao and A. M. Niknejad, "Near-field power transfer and backscattering communication to miniature RFID tag in $65 \mathrm{~nm}$ CMOS technology," 2016 IEEE MTT-S International Microwave Symposium (IMS), San Francisco, CA, 2016, pp. 1-4.

[13] X. Chen, W. G. Yeoh, Y. B. Choi, H. Li and R. Singh, "A 2.45-GHz Near-Field RFID System With Passive OnChip Antenna Tags," in IEEE Transactions on Microwave Theory and Techniques, vol. 56, no. 6, pp. 1397-1404, June 2008.

[14] L. H. Guo et al., "A small OCA on a 1/spl times/0.5-mm/sup 2/ 2.45-GHz RFID Tag-design and integration based on a CMOS-compatible manufacturing technology," in IEEE Electron Device Letters, vol. 27, no. 2, pp. 96-98, Feb. 2006

[15] Wooi Gan Yeoh et al., "A 2.45-GHz RFID tag with on-chip antenna," IEEE Radio Frequency Integrated Circuits (RFIC) Symposium, 2006, San Francisco, CA, 2006, pp. 4.

[16] L. H. Guo et al., "Design and Manufacturing of Small Area On-Chip-Antenna (OCA) for RFID Tags," 2006 European Solid-State Device Research Conference, Montreux, 2006, pp. 198-201.

[17] Beh, T., Kato, M., Imura, T., \& Hori, Y. "Wireless Power Transfer System via Magnetic Resonant Coupling at Fixed Resonance Frequency-Power Transfer System Based on Impedance Matching-”. World Electr. Veh. J. 4(4), 744-753. 2010.

[18] Khan, S. R., \& Choi, G. "Analysis and Optimization of Four-Coil Planar Magnetically Coupled Printed Spiral Resonators". Sensors. 2016.

[19] Sah, A. K., \& Pant, D. R. Analysis and Optimization of Wireless Power Transfer Link Inductance, Proceedings of IOE Graduate Conference 2014. 82-93. 2014.

[20] Pirouznia, P., \& Ganji, B. A. Analytical Optimization of High Performance and High Quality Factor MEMS Spiral Inductor, Progress In Electromagnetics Research. 34, 171-179. February 2014.

[21] U. Jow and M. Ghovanloo, "Design and Optimization of Printed Spiral Coils for Efficient Transcutaneous Inductive Power Transmission," in IEEE Transactions on Biomedical Circuits and Systems, vol. 1, no. 3, pp. 193202, Sept. 2007.

[22] S. S. Mohan, M. del Mar Hershenson, S. P. Boyd and T. H. Lee, "Simple accurate expressions for planar spiral inductances," in IEEE Journal of Solid-State Circuits, vol. 34, no. 10, pp. 1419-1424, Oct. 1999.

[23] F. Jolani, Y. Yu and Z. Chen, "A Planar Magnetically Coupled Resonant Wireless Power Transfer System Using Printed Spiral Coils," in IEEE Antennas and Wireless Propagation Letters, vol. 13, pp. 1648-1651, 2014.

[24] Jolani, F., Yu, Y., \& Chen, Z. D. (n.d.). Electromagnetic Modeling and Optimization of Magnetic Resonant Coupling Wireless Power Transfer Using Coil Array. 2015 IEEE MTT-S International Conference on Numerical Electromagnetic and Multiphysics Modeling and Optimization (NEMO), 1, 1-3.

[25] Saberhosseini, S. S., Ganji, B. A., Razeghi, A., \& Mahmoudi, Z. (2016). Modeling \& simulation of MEMS spiral inductor. 2016 24th Iranian Conference on Electrical Engineering, ICEE 2016, 507-510. https://doi.org/10.1109/IranianCEE.2016.7585574. 
[26] Y. Wang, J. Song, L. Lin, X. Wu and W. Zhang, "Research on magnetic coupling resonance wireless power transfer system with variable coil structure," 2017 IEEE PELS Workshop on Emerging Technologies: Wireless Power Transfer (WoW), Chongqing, 2017, pp. 1-6.

[27] A. Trigui, S. Hached, F. Mounaim, A. C. Ammari and M. Sawan, "Inductive Power Transfer System With SelfCalibrated Primary Resonant Frequency," in IEEE Transactions on Power Electronics, vol. 30, no. 11, pp. 60786087, Nov. 2015

[28] Farid, J. Wireless Power Transfer via Magnetic Resonant Coupling. Halifax, Nova Scotia. 2015.

[29] Issue, S. T. H. E. "Wireless Power Transmission, Technology, and Applications", Wireless Power Transfer-Concepts and Applications. 101(6), 1271-1275. 2013.

[30] I. Cho, S. Kim, J. Moon, J. Yoon, W. Byun and H. Choi, "Miniature magnetic resonance coils for wide wireless power transfer applications," 2014 IEEE Conference on Antenna Measurements \& Applications (CAMA), Antibes Juan-les-Pins, 2014, pp. 1-3.

\section{BIOGRAPHIES OF AUTHORS}
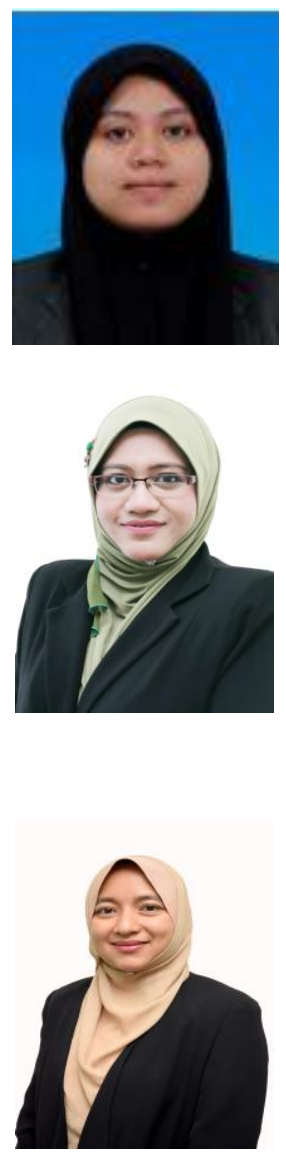

Saidatul Izyanie Kamarudin obtained her Bachelor of Engineering in Communication Engineering (Honors) from International Islamic University Malaysia, Malaysia. In 2013, she received her Master of Science in Communication System Engineering from University of Portsmouth, Portsmouth, United Kingdom. Then, in 2014, she has joined the Department of Electrical Engineering at University of Liverpool as a Researcher before pursuing her $\mathrm{PhD}$ studies at the Department of Computer and Communication System Engineering, University Putra Malaysia, Selangor. She is currently doing a research in Magnetic Resonance Coupling Wireless Power Transfer for 5G Application at Wireless and Photonic Network Research Centre of Excellent (WipNet) Laboratory at UPM.

Alyani Ismail (M’06) received her BEng (Hons) in electronic and information engineering from University of Huddersfield, United Kingdom in 1999. She received her MSc in Communication, Computer and Human- Centred Systems Engineering in 2001 and her PhD in Electronics Engineering majoring in micromachined microwave devices in 2006 from University of Wales, UK. Her research in micromachined filter design at Birmingham was sponsored by the UK Engineering and Physical Science Research Council. From 2006 to 2011, she was a lecturer with Faculty of Engineering, Universiti Putra Malaysia and since 2011, she has been an Associate Professor with the same faculty. She is the author of more than 200 articles, and more than 50 proceedings. Her research interest specializes in the development of microwave devices particularly passive filters and antennas, dielectric properties of materials for $\mathrm{RF} /$ microwave applications, and engineering education.

Ir. Dr. Aduwati Sali is currently an Associate Professor at Department of Computer and Communication Systems, Faculty of Engineering, Universiti Putra Malaysia (UPM) since Dec 2013. She is also a Deputy Director at UPM Research Management Centre (RMC) responsible for Research Planning and Knowledge Management. She obtained her PhD in Mobile and Satellite Communications from University of Surrey, UK, in July 2009; MSc in Communications and Network Engineering from UPM, Malaysia, in April 2002 and BEng in Electrical Electronics Engineering (Communications) from University of Edinburgh, UK, in 1999. She is also a Chartered Engineer (C. Eng) registered under UK Engineering Council and a Professional Engineer (P. Eng.) under Board of Engineers Malaysia (BEM). She worked as an Assistant Manager with Telekom Malaysia Bhd from 1999 until 2000. She is involved with IEEE as a Chair to ComSoc/VTS Malaysia (2017 and 2018) and Young Professionals (YP) (2015); Young Scientists Network-Academy of Sciences Malaysia (YSN-ASM) as Chair (2018) and Co-Chair (2017) for Science Policy. She is also the recipient of 2018 Top Research Scientists Malaysia (TRSM) Award from Academy of Sciences Malaysia (ASM). Aduwati was involved with EUIST Satellite Network of Excellence (SatNEx) I \& II from 2004 until 2009. She is the principle investigator and collaborator for projects under the local and international funding bodies; namely Malaysian Ministry of Science, Technology and Innovation (MOSTI), Malaysian Ministry of Higher Education (MoHE), Malaysian Communications and Multimedia Commission (MCMC), Research University Grant Scheme (RUGS) (now known as Putra Initiative Grant) UPM, The Academy of Sciences for the Developing World (TWASCOMSTECH) Joint Grants, EU Horizon2020 Research and Innovation Staff Exchange (H2020RISE) and NICT Japan - ASEAN IVO. She gave consultations to Malaysian Ministry of Information and Multimedia, Malaysian Ministry of Higher Education, National Space Agency (ANGKASA), ATSB Bhd and Petronas Bhd. on projects related to mobile and satellite communications. Her research interests are radio resource management, MAC layer protocols, satellite communications, satellite-assisted emergency communications, IoT systems for environmental monitoring and 3D video transmission over wireless networks. In 2014, the 
fateful event of missing MH370 has requested her to be in printed and broadcasting media, specifically Astro Awani, RTM, TV Al-Hijrah, BERNAMA, Harian Metro and Metro Ahad, regarding analysis on satellite communication in tracking the aircraft.

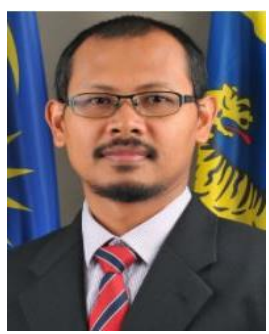

Dr. Mohd Yazed Ahmad (M'12) received the B.E. degree in electrical engineering from the Department of Electrical Engineering, University of Malaya, Kuala Lumpur, Malaysia, in 2003, theM.Eng.Sc. degree (Instrumentation) from the Department of Biomedical Engineering, Faculty of Engineering, University of Malaya, in 2006, and the Ph.D. degree in electrical engineering science from the University of Technology, Sydney, NSW, Australia, in 2013. He is currently a Senior Lecturer with the Department of Biomedical Engineering, Faculty of Engineering, University of Malaya. His current research interests include wireless power transfer, RFID, instrumentation, smart space, and IOT systems. 